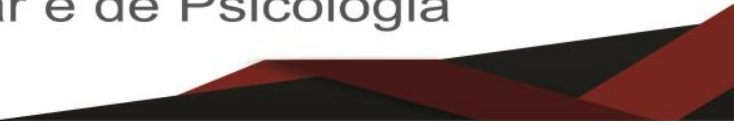

Estudo de Caso

\title{
A Influência da Psicopedagogia na Aprendizagem dos Alunos da Escola Municipal João Felix de Abreu: Um Estudo de Caso
}

\author{
Cybele Batista de Lima Arraes ${ }^{1}$; Maria Jucilene Lopes Leite ${ }^{2}$
}

\begin{abstract}
Resumo: No complexo processo que envolve a aprendizagem, revela-se significante a atuação preventiva do psicopedagogo no contexto escolar, onde muitas informações e vários aspectos têm que ser observados e analisados. Ter conhecimento de como o aluno constrói o seu saber, compreender as dimensões das relações com a escola, com os professores, com o conteúdo e relacioná-los aos aspectos afetivos e cognitivos, permitindo um fazer mais fidedigno ao psicopedagogo. Deve-se considerar que o desenvolvimento do aprendente se dá de forma harmoniosa e equilibrada nas diferentes condições orgânica, emocional, cognitiva e social. Trata-se de uma pesquisa de enfoque qualitativo, indutivo, um estudo de caso, que tem por objetivo analisar a influência que tem a psicopedagogia na aprendizagem dos alunos da escolamunicipal João Felix de Abreu, localizada na cidade de Araripina, Pernambuco, Brasil.
\end{abstract}

Palavras-chave: Psicopedagogia; Atuação e intervenção, Aluno; Aprendizagem; Escola.

\section{A Influência da Psicopedagogia na Aprendizagem dos Alunos da Escola Municipal João Felix de Abreu - Um Estudo de Caso}

Resumo: No complexo processo que envolve a aprendizagem, revela-se significante a atuação preventiva do psicopedagogo no contexto escolar, onde muitas informações e vários aspectos têm que ser observados e analisados. Ter conhecimento de como o aluno constrói o seu saber, compreender as dimensões das relações com a escola, com os professores, com o conteúdo e relacioná-los aos aspectos afetivos e cognitivos, permitindo um fazer mais fidedigno ao psicopedagogo. Deve-se considerar que o desenvolvimento do aprendente se dá de forma harmoniosa e equilibrada nas diferentes condições orgânica, emocional, cognitiva e social. Trata-se de uma pesquisa de enfoque qualitativo, indutivo, um estudo de caso, que tem por objetivo analisar a influência que tem a psicopedagogia na aprendizagem dos alunos da escolamunicipal João Felix de Abreu, localizada na cidade de Araripina, Pernambuco, Brasil.

Palavras chave: Psicopedagogia; Atuação e intervenção, Aluno; Aprendizagem; Escola.

\footnotetext{
${ }^{1}$ Doutora em Ciências da Educação pela Universidade Hispano Guarany, Assunção - Paraguay. Contato: cybarraes@ hotmail.com;

2 Doutora em Ciências da Educação; Mestre em Ciências da Educação; Pós-Graduada em Metodologia do Ensino Superior e Gestão de Instituições Educativas; Graduada em Letras; Professora Universitária da Autarquia Educacional do Araripe - AEDA. E-mail: jucilenelopes@bol.com.br.
} 


\section{Introdução}

Este estudo procura refletir sobre a influência que tem a psicopedagogia na aprendizagem dos alunos da escola municipal João Felix de Abreu, na cidade de Araripina, Pernambuco.

Ao estudar os aportes teóricos da psicopedagogia, pode-se constatar, especialmente, a presença dos trabalhos de autores como: Jorge Visca, Alicia Fernández e Marina Müller. Assim, por exemplo, em seu artigo "Perspectivas de psicopedagogia em elcomienzo del milenio", Müller (1995) comenta que na Universidade de Salvador, há cinco décadas, surgiu a psicopedagogia como uma disciplina. Disciplina esta, que trabalha com a aprendizagem, como atividade que inclui a relação entre ensino e aprendizagem, em contextos sistemáticos ou não. Deste modo, nasceu a psicopedagogia como carreira universitária de três anos, no ano de 1956.

Para tanto, a Psicopedagogia surge para auxiliar na intervenção e prevenção dos problemas de aprendizagem dos alunos. Tanto na clínica quanto na instituição, o psicopedagogo atua intervindo como mediador entre o sujeito e sua história traumática, ou seja, a história que lhe causou a dificuldade de aprender. No entanto, o profissional não deve fazer parte do contexto do sujeito, já que ele está contido numa dinâmica familiar, escolar ou social da qual o profissional deve manter-se ciente do problema de aprendizagem, fazer a leitura e a intervenção no mesmo.

Já o trabalho preventivo, objetiva evitar os problemas de aprendizagem, enfatizando a instituição escolar, os processos didáticos e metodológicos, a dinâmica institucional com todos profissionais nela inseridos. Desde o nascimento, o indivíduo faz parte de uma instituição social organizada, a família, e depois, ao longo da vida, integra-se às outras instituições.Nessa interação vai se construindo uma teia de saberes, onde todos os membros da sociedade são parceiros possíveis, contribuindo cada um com seus conhecimentos, suas práticas, seus valores e suas crenças.

\section{A Psicopedagogia}

A psicopedagogia surgiu no Brasil devido ao grande número de crianças com fracasso escolar. O psicopedagogo é o profissional preparado para realizar avaliações psicopedagógicas, diagnosticar os problemas de aprendizagem, utilizando métodos e instrumentos próprios da psicopedagogia, juntamente com uma equipe multidisciplinar. Antes dessas informações, buscam-se estudos que abordem a influência da psicopedagogia na aprendizagem escolar.

Balensiefer e Santos (2013) argumentam que na prática psicopedagógica é preciso valorizar os esforços de profissionais preocupados com as dificuldades de aprendizagem dos alunos. Pouco se tem verificado quanto à importância de profissionais ligados ao trabalho psicopedagógico nas escolas 
empenhadas não só no propósito de resgatar crianças com dificuldades, mas também sensibilizar professores e os pais para essa problemática, no sentido de prevenir às dificuldades e também encaminhar os alunos para atendimento especializado, quando necessário.

Com base na literatura consultada sobre o tema, além do estudo acima referenciado, existem antecedentes que falam de várias investigações levadas a cabo sobre o tema. Porém estudos específicos como o que se desenvolve neste trabalho não têm antecedentes na instituição investigada.

\section{Psicopedagogia em âmbito escolar}

Nas escolas públicas existem sempre problemas dos mais diversos tipos para ser tratado e resolvido, isso é histórico e faz parte da realidade de todos os atores envolvidos no ambiente escolar. No entanto, algumas escolas conseguem sanar grande parte desses problemas, seja de caráter estrutural, funcional e/ou organizacional, que assolam as instituições escolares. Para tanto, é preciso levar em consideração a gestão escolar, esta pode fazer toda a diferença em uma instituição educacional pública. Um grupo gestor participativo pode garantir à escola uma integração ideal com a sociedade, com a comunidade cientifica e com as políticas públicas voltadas para a melhoria da educação. Luck (2000), afirma que,

[...] os sistemas educacionais, como um todo, e os estabelecimentos de ensino, como unidades sociais especiais, são organismos vivos e dinâmicos, fazendo parte de um contexto socioeconômico- cultural marcado não só pela pluralidade, como pela controvérsia que vêm, também, a se manifestar na escola; portanto, com tais características devem ser também as escolas entendidas. Ao serem vistas como organizações vivas, caracterizadas por uma rede de relações entre todos os elementos que nelas atuam ou interferem direta ou indiretamente (LÜCK, 2000, p. 14).

É de vital importância à escola para o processo de ensino/aprendizagem, e os fatores como: sala de aula, professor, grupo gestor, infraestrutura e principalmente os alunos, são o cerne da educação.

De acordo com “a ação pedagógica, portanto, não se refere apenas ao - como se faz - mas, principalmente, ao - por que se faz - orientando o trabalho educativo para as finalidades sociais e políticas almejadas pelo grupo de educadores". (LIBÂNEO, 2004, p. 150).

Através das ações pedagógicas o professor pode contribuir para que o aluno possa ser agente transformador de sua própria realidade, aprendendo assim a essência de se fazer algo para seu crescimento intelectual, social e político. Somado a esse caráter histórico de valores e comportamentos 
sociais, percebe-se que a escola em sua constituição como uma instituição social, tem o papel de conduzir todo um processo de organização voltado para o estudo científico.

Com isso, será inevitável não perceber que o professor tem grande responsabilidade em toda essa ligação de fatores voltados para a instituição escolar.

[...] refletindo-se um pouco mais sobre essa atuação do professor e pensando a relação que instaura a docência e, por conseguinte, a condição docente em sua realização nas sociedades modernas e contemporâneas, é preciso considerar a escola. É ela, via de regra o lócus fundamental em que a condição docente se realiza. É ela, a sala de aula, o espaço no qual, docentes e discentes interagem, convivendo durante a maior parte de seus tempos escolares (TEIXEIRA, 2007, p. 434).

Aprende-se também que, a influência do professor como um profissional da educação, vai além dos muros de qualquer instituição de ensino, podendo mudar vidas, conceitos, pensamentos e até mesmo o mundo, o saber de que não pode duvidar um momento sequer na minha prática educativocrítica é de que, como experiência especificamente humana, a educação é uma forma de intervenção no mundo. (FREIRE, 1996, p. 98).

O trabalho psicopedagógico, como assinala Scoz (1994), pode estar voltados para assessoria de professores e de demais educadores, nas escolas, com o objetivo de contribuir para a melhoria do trabalho docente, ampliando as perspectivas de análise das questões pedagógicas e alternativas de trabalho. Lembra Scoz (1994), analisando a intervenção psicopedagógica nas escolas, que:

[...] a prática evidência que nem as estruturas cognitivas, nem a afetividade e nem a influência do meio social por si só, conseguem explicar os processos normais e patológicos da aprendizagem, enquanto que a integração desses fatores oferece uma visão mais ampla e profunda (SCOZ, 1994,p.28).

Na opinião de Weiss (2008), a má qualidade no ensino provoca um desestimulo na busca do conhecimento.Ainda se ver nas escolas, professores usando materiais de ensino desestimulante, desatualizados, desprovidos de significados para os estudantes, sem levarem conta suas diferenças individuais. O relacionamento professor-aluno-escola, as classes superlotadas, as avaliações, a metodologia, os objetivos de seu ensino, a infraestrutura escolar, são vários aspectos que envolvem o processo de ensino-aprendizagem e desta forma fica difícil à assimilação de conhecimentos.

E por uma associação de fatores que determina o fracasso escolar. Weiss (2008) considera sob três perspectivas o fracasso escolar, ou se quiser dizer de outra forma, aprendizagem mal sucedida, a não aprendizagem ou distúrbios, problemas ou dificuldades. Sinaliza, pois, sob a perspectiva da sociedade, da perspectiva da escola e da perspectiva do aluno.

Na perspectiva da sociedade, considerada mais ampla, estariam o tipo de cultura, as condições e relações político-sociais e econômicas vigentes, o tipo de estrutura social, as ideologias dominantes 
e as relações implícitas ou explicitas.O nível de adaptação, integração ou isolamento do contexto em que vivem o aluno e sua família destes aspectos com a educação escolar.

Na perspectiva escolar, diz respeito à análise da instituição escolar, em seus diferentes níveis: a equipe de professores e as matérias; as expectativas quanto aos alunos ou a turma, os resultados, a generalização, ou limitação dos conflitos que aparecem de conduta relacional e de aprendizagem, os modelos didáticos e os critérios de avaliação, a flexibilidade para adaptar o currículo e os processos de ensino- aprendizagem e a infraestrutura.

$\mathrm{Na}$ perspectiva do aluno enquanto aprendente, isto é, especificamente às suas condições internas de aprendizagem, focando-se, assim, a questão da intra-subjetividade, considerando o seu potencial cognitivo e motor, sua situação emocional, sua autoestima e autoconceito geral, que estão presentes na aprendizagem escolar.

A escola, instituição, a qual cumpre uma importante função social que é promover o desenvolvimento cognitivo e socializar os conhecimentos disponíveis, para que através da aprendizagem o sujeito seja inserido, de forma mais organizada e ativa no mundo. No entanto, a escola é considerada responsável por grande parte da formação do ser humano.

Há muito, o que se faz no interior da escola para que o aluno encontre os meios suficientes e adequados para a autêntica aprendizagem e o psicopedagogo é o profissional que pode ajudar "na dinâmica inter- relacional da instituição".

\begin{abstract}
Menciono as tentativas de explicação para o fracasso escolar por outras vias que não a pedagogia e a psicologia. [...] os fatores etiológicos utilizados para explicar índices alarmantes do fracasso escolar envolviam quase que exclusivamente fatores individuais etc. [...] No Brasil, particularmente durante a década de 70 , foi amplamente difundido o rótulo de Disfunção Cerebral Mínima para as crianças que apresentavam, como sintoma proeminente, distúrbios na escolaridade (KIGUEL apud BOSSA, 2000, p. 18-19).
\end{abstract}

A escola precisa está sendo constantemente revista, reorganizada parase adequar em função de sua clientela. Assim o trabalho do psicopedagogo na instituição escolar tem um caráter preventivo e terapêutico, no sentido de procurar criar competências e habilidades para solução dos problemas. Para tanto, prioridades devem ser estabelecidas, dentre elas: diagnóstico e busca da identidade da escola, definições de papéis na dinâmica relacional em busca de funções e identidades, diante do aprender, análise do conteúdo e reconstrução conceitual, além do papel da escola no diálogo com a família.

Os conteúdos escolares são necessários, mas para que possam promover aprendizagem, o professor precisa saber distinguir por quais meios esses conteúdos são acessíveis ás crianças. Tudo depende da etapa de desenvolvimento. Sem 
conhecer as características que definem tais etapas, torna-se mais difícil ensinar a criança de modo que ela aprenda (SEBER,1995,p.231).

[...] o psicopedagogo não é um mero "resolvedor" de problemas, mas um profissional dentro de seus limites e de sua especificidade pode ajudar a escola a remover obstáculos que se interpõem entre os sujeitos e o conhecimento e a formar cidadãos por meio da construção de práticas educativas que favoreçam processos de humanização e reapropriação da capacidade de pensamento crítico (TANAMACHI, 2003, p. 43).

A família na sua visão do aluno de sua situação e de seu aproveitamento, o equilíbrio entre as expectativas, os auxílios que podem oferecer e o modelo de relação com a escola que podem propiciar (construtivo, colaborador, de enfrentamento, de inibição); dessa forma, o trabalho da psicopedagogia quando encontra consonância e parcerias na escola, promove efeitos positivos para a minimização das dificuldades que emergem no contexto escolar, apesar de representar um constante desafio, pois requer o envolvimento de toda a equipe, e um desejo permanente de mudanças, para que as transformações, de fato, ocorram.

\section{A avaliação psicopedagógica}

O processo de ensino aprendizagem mostra como cada pessoa e grupo de aprendizagem são únicos e podem se desenvolver com diferenças significativas, não apenas pela diversidade de habilidades físicas e cognitivas, mas também emocionais manifestadas nas aptidões e relacionais solidárias e de convivência, cujo desenvolvimento atitudes, inibição ou repressão podem influenciar os contextos.

A avaliação psicopedagógica é a primeira ação do psicopedagogo, requer um processo prévio de obtenção de dados e informações sobre o que se pretende conhecer e melhorar a aprendizagem do sujeito. Trata-se de um processo amplo que deve ser compartilhado e incluir diferentes contribuições profissionais.

O psicopedagogo tem um papel fundamental no processo de avaliação e intervenção dos indivíduos portadores das desordens da aprendizagem, pois ele tem o conhecimento tanto na área psicológica quanto na área pedagógica. Precisa ter espirito investigativo e levantar hipóteses. Aplicar testes e avaliar o contexto no qual o indivíduo que apresenta tais dificuldades está inserido e poderá auxiliá-lo em seu pleno desenvolvimento. Uma boa avaliação psicopedagógica, fazendo entrevistas, aplicando os testes, visitando a escola, fazendo anamnese com os pais ou com o próprio cliente e fechando sua hipótese diagnóstica, fazendo a devolução com os pais por meio de um informe psicopedagógico. 
Dando continuidade ao trabalho psicopedagógico clínico, o psicopedagogo, deve iniciar então seus trabalhos de intervenção, visando auxiliar seu cliente na evolução de seu quadro, trabalhando com os jogos, com a estimulação das múltiplas inteligências e com as técnicas de PNL Programação Neurolinguística.

O psicopedagogo avalia e apresenta conclusões sobre um determinado aluno, turma e escola. Trata-se de uma informação valiosa que é preciso levar em consideração para depois tomar as decisões coordenadas; o diagnóstico, a devolutiva e a intervenção se preciso for. Por meio do processo de intervenção e do acompanhamento psicopedagógico, estabelece-se uma avaliação continua, não apenas do processo dinâmico de ensino-aprendizagem, mas de todos os elementos endógenos e exógenos que o afetam.

A Avaliação psicopedagógica é pratica e útil quando apresenta conclusões e serve de base para edificar novas propostas dirigidas a cada âmbito de análise; o aluno e o grupo em seus contextos familiares, escolar e social que, por sua vez, estão em interação. Por isso, jamais se pode entendê-la como um processo à margem, visto que a avaliação acontece no início eé contínua, faz parte e surge de um trabalho profissional que deve ser necessariamente compartilhado, o que implica tomar decisões e adotar medidas conjuntas em que cada profissional ofereça a contribuição que lhes cabe.

\section{Metodologia}

Trata-se de um estudo de campo qualitativo, na Escola João Felix de Abreu. Uma instituição educacional pública municipal situada na Lagoa de dentro, zona rural do município de Araripina. Em 2015, atendeu 145 alunos, assim distribuídos: Infantil I, 27 alunos; Infantil II, 22 alunos; $1^{\circ}$ ano do ensino fundamental, 16 alunos; $2^{\circ}$ ano do ensino fundamental, 20 alunos; $3^{\circ}$ ano do ensino fundamental, 14 alunos; $4^{\circ}$ ano do ensino fundamental, 17 alunos; $5^{\circ}$ ano do ensino fundamental, 29 alunos.

A amostra constou de 01diretora, 60 alunos e 06 professoras. Os dados foram coletados através de documentos oficiais e da aplicação de questionários, a alunos, professores e diretora. O processamento dos dados foi efetuado por meio de ferramentas que descrevem a organização da investigação com uma visão geral dos resultados e destaca a maneira que vai processar e analisar.

Utilizou-se para isso a análise de conteúdo, uma metodologia aplicada para analisar dados quantitativos e qualitativos, onde se busca compreender os objetivos dos estudos realizados. Segundo Rauen (1999, p. 141), é a parte que apresenta os resultados obtidos na pesquisa e analisa-os sob o crivo dos objetivos e/ou das hipóteses. Assim, apresentação dos dados é a evidência das conclusões e a interpretação consiste no contrabalanço dos dados com a teoria. 
A análise de conteúdo busca de forma sistematizada, proporcionar maior objetividade, de forma a validar possíveis descobertas. Para Severino (2007, p.121), análise de conteúdo "é uma metodologia de tratamento e análise de informação a constante de um documento, sob as formas de discursos pronunciados em diferentes linguagens". Os dados coletados foram tabulados e analisados a luz da teoria de diversos autores que compuseram o marco teórico desse trabalho.

\section{Resultados}

\section{A forma de atuação dos psicopedagogos da escola acerca de suas práticas}

No tocante a criatividade no desempenho das atividades de ensino e inovação, os professores e diretora disseram:

1. Fazemos projetos e propostas de trabalho interessante que envolve o aluno, a família, e a comunidade, buscando incentivar novas buscas, novas descobertas, compreensões e reconstruções do conhecimento. (D);

2. Nós sempre estamos elaborando um projeto diferente para resgatar o aluno e motivá-lo. (P.1)

3. Acredito que o ensino aprendizagem é uma via de mão dupla, então precisamos atuar afetivamente compreendendo a situação do aluno. (P.2);

4. A psicopedagogia para mim, fez com que eu conhecesse melhor cada indivíduo, atuando como professor, afetivo-social-cognitivo. (P.3);

5. Aqui na escola temos uma visão do todo, não julgamos o indivíduo, envolvemos em atividades na perspectiva de transformá-lo para atuar na sociedade. (P4);

6. Levamos sempre em conta as realidades internas e externas por isso trabalharam com projetos em grupo, envolvendo a sociedade e a família. (P.5);

7. Buscamos através da interação família, escola e sociedade o sentido dos conteúdos vivenciados em sala de aula, assim, une o científico com a prática de mundo. (P.6)

Ao analisar as respostas dadas pelos pesquisados compreende-se que estão bem empenhados em inovar o ensino, para que se possa assim melhorar o desempenho dos alunos, que por razões diversas encontram- se com um baixo índice de aprendizagem, entre outros problemas. Muitos foram os projetos de intervenção elaborados para resolução do problema, sem resposta. 
O acompanhamento dos pais tende a criar um ambiente familiar, favorável que pode influenciar na aprendizagem e no sucesso, a relação sucesso escolar e desenvolvimento social do aluno como resultantes do envolvimento família e escola. O exemplo, a ausência dos pais na vida acadêmica da criança pode contribuir para a baixa autoestima e problemas na aprendizagem do aluno. É por meio das relações familiares e tempo de convívio que o indivíduo se reconhece como ser e se faz conhecido; estabelecem-se as primeiras regras e padrões culturais que o regem na sociedade; se favorecido, ocorre o amadurecimento psíquico, bem como transformações individual e coletiva em consonância com os padrões socioculturais em que se vive (CASARIN; RAMOS, 2007).

\section{Sobre a influência da psicopedagogia na sua forma de atuar na escola}

8. A escola não é isolada da sociedade, analisaremos as observações feitas com um pouco mais de cuidado, para não agredir em nenhum sentido a integridade física, moral elou intelectualde quem quer que seja, dentro das atribuições da possível intervenção, mas sentimos a necessidade de ajudar, percebendo o aluno nas diversas áreas cognitiva-social-emocional. (D)

9. A psicopedagogia nos orienta através de oficinas como nova forma de vivência, como nova forma de aprender. (P.2);

10. Através da releitura, ressignificando o sistema de recuperação e reintegração do aluno no processo. (P.3);

11. Nas sugestões sobre os trabalhos coletivos e os valores, culturais $e$ individuais relacionados a um posicionamento crítico sobre questões outras a formação humanista. (P.4);

12. Orientações sobre comportamentos sociais, os valores e suas influências no universo escolar. (P.5*);

13. Na orientação para trabalhar as diversidades culturais e as diferenças sociais. (P.6);

14. No meu ponto de vista, a psicopedagogia, nos ajuda na forma de pensar e agir em relação aos alunos na prevenção e tratamento das dificuldades de aprendizagem, trabalhou com projetos de intervenção. (P.7).

No ponto de vista dos pesquisados sobre a influência da psicopedagogia na forma de atuação na escola, eles descrevem, que há uma necessidade de compreender as dificuldades de aprendizagem do aluno. A partir deste diagnóstico sente-se a necessidade de um reensino que sejam trabalhadas atividades diferenciadas e criativas que atendam as especificidades de cada aluno, de forma que envolvam, não só os ensinamentos conceituais, mais a base do convívio social e familiar, desenvolvendo os aspectos afetivo-cognitivos, sociais e motores.

[...] "reencontro do sujeitocom o anseio pelo saber, pois em algum lugar ela(criança) o perdeu".Assim sendo, a função do psicopedagogodireciona-se à 
escuta e observação atenta dasdificuldades, além de propor alterações nasposturas das famílias e, mais diretamente, dosprofissionais que atuam com os alunos.A relação professor-aluno deve ser construídacotidianamente, no fazer profissional. No âmbitoestrito da psicopedagogia clínica e institucional, no relacionamento estabelecido entre estesindivíduos são fundamentais para a construção oureconstrução da natureza do aprender, isto é, ovínculo estabelecido deve ser percebido comoadequado, prazeroso e saudável. O apreender do significado está tambémdiretamente relacionado à existência de docentespreparados, conscientes de seus papéis deestimuladores, fomentadores, instigadores dacuriosidade e da criatividade. (CASTRO, 2004, p.111).

Como acontece à intervenção da psicopedagogia na escola

15. Para a realização da intervenção, nós trabalhamos atividades relacionadas diretamente com uma proposta e gerou o projeto, e para isso essas atividades foram construídas seguindo uma sistematização dessa proposta. Nessa perspectiva, buscaremos as mais diversificadas atividades para ajudar na aprendizagem do sujeito em razão aos aspectos pedagógicos elou psicológicos, aspectos afetivos elou cognitivos abrangendo os três níveis de modalidade da intervenção: nível individual, nível coletivo e nível da escola. (D);

16. Através da percepção das dificuldades de aprendizagem, fazemos atividades para serem desenvolvidas que estimulam o aprender. (P1);

17. Quando diagnosticamos algumas dificuldades de aprendizagem, elaboramos projetos de intervenção a respeito daquela dificuldade para ajudar o aluno no entendimento. (P2);

18. Implantamos uma proposta de intervenção psicopedagógica, quando detectado dificuldade na aprendizagem usando diversos recursos, se afastando do tradicional e inovando. (P3);

19. Sabemos que nas relações sociais e na interação com o meio e através dos conhecimentos adquiridos, o currículo, programas e conteúdo da intervenção psicopedagógica acontece. (P4);

20. A intervenção psicopedagógica revoluciona a inter- relação professoraluno. Um ambiente aberto ao questionamento ao diálogo encoraja os alunos a ser criativo autônomo. (P5);

21. O trabalho em equipe é muito privilegiado, elimina a individualidade $e$ trabalha intervindo no social, no cognitivo e na emoção. (P6);

Analisando a fala dos segmentos da escola participantes desta pesquisa, quando indagam sobre a intervenção no ambiente escolar na perspectiva de resolução das dificuldades de aprendizagem dos alunos, além dos projetos interventivos já utilizados pelos professores, necessário se faz a intervenção curativa, objetivando diagnosticar intervindo individualmente nas necessidades destes alunos. 
Solé afirma que, essa intervenção tem um maior alcance quando realizada no ambiente em que o aluno desenvolve suas atividades e por meio das pessoas que, cotidianamente, se relacionam com ele, uma vez que os processos de aprendizagem se relacionam diretamente com a socialização e integração dos alunos no contexto sócio - educacional em que estes estão inseridos. (SOLÉ, 2000, p. 29).

\section{Quando perguntado em relação aos recursos utilizados para a atuação da psicopedagogia na escola}

22. Quando desenvolvemos os projetos que precisam de recursos, fazemos uma lista das necessidades e a gestão nos oferece. (P1);

23. Para a utilização de recursos, cabe estar relacionado no projeto de intervenção que mandamos para o gestor. (P2);

24. De acordo com o planejamento do projeto de intervenção fazemos uma relação dasnecessidades para realizar o mesmo. (P3);

25. Os professores fazem um projeto e enviam para mim, para que eu possa organizar os recursos que necessitam. Estes materiais utilizados nos projetos são diversos: materiais pedagógicos, passeios, entre, jogos confecção de vestuário, dentre outros. (D);

26. Trabalhamos com diversos recursos, depende do tipo de projeto que iremos desenvolver com o aluno, como: cinema, teatro, jogos, visita de campo, etc. (P4);

27. Acho muito importante estes tipos de recursos diferentes: reabilitação da leitura, reabilitação da escrita, reabilitação motora, técnica de concentração e memória, jogos de leitura, jogos de matemática, brinquedos, fantoches, jogo de regras e outros. (P5);

28. Utilizamos diversos recursos materiais para desenvolver os projetos. Depende do tipo de projeto que faremos. (P6).

Compreende-se diante das respostas dadas pelos sujeitos da pesquisa, que não há dificuldades em relação aos instrumentos pedagógicos necessários aos projetos elaborados pelos professores. Como bem coloca a gestora da escola em sua fala, os professores recebem à medida que solicitam para realização das suas atividades. Percebe-se também que são variados os projetos e os instrumentos fornecidos para utilização por parte deles.

Ninguém aprende e apreende sem afeto, sem desejo, sem curiosidade e sem vivenciar objetivamente o conteúdo em questão. Sem conseguir ressignificar, internamente de maneira única e intransferível, o conhecimento. Portanto, a contextualização e as referências frequentes à vida cotidiana do jovem adolescente devem fazer parte do processo de aprendizagem Entende-se que a função do psicopedagogo é investigar todas as variáveis possíveis existentes no processo de 
aprendizagem, a fim de orientar as famílias para aresolução de conflitos, inclusive de natureza afetiva- emocional. (CASTRO, 2004, p.111).

A base de todo processo de aprendizagem, a relação professor-aluno pode ser caracterizada como um "ser que ensina e um ser que aprende", ou "seres que ensinam-aprendem", dentre outras formas. Deve ser constituída como relação de troca de conteúdos, de conhecimentos, de afeto. (CASTRO, 2004, p.110).

\section{Como os alunos estão aceitando as práticas da psicopedagogia na escola}

Quando foram perguntados sobre a aprendizagem dos alunos

1. Estamos percebendo que os resultados são positivos quanto à aprendizagem, pois, a ação interventiva do psicopedagogo ressalta a aprendizagem múltipla construída no contexto do sujeito, o aproveitamento de antigas aquisições e a sua reestruturação psicológica, por intermédio da crença na sua capacidade de aprender sempre.(D);

2 Percebo que houve uma melhoria na aprendizagem em todos os níveis cognitivo, social e emotivo.(Pl);

3. Hoje sinto uma maior integração do aluno, dos pais, da comunidade com o ambiente escolar, fazendo assim uma aprendizagem proveitosa. (P2);

4. De acordo com os resultados de aprovação, reprovação e rendimento escolar houve um aumento no resultado.(P3);

5. Estou satisfeita com o rendimento dos meus alunos. (P4);

6. Vejo positivo o rendimento dos meus alunos, principalmente em construirmos junta a aprendizagem, quando vejo o brilho nos olhos quando percebo a descoberta do conhecer. (P5);

7. Fico muito feliz por garantir a inclusão dos alunos com necessidades especiais, proporcionando condições de desenvolver suas habilidades cognitivas e psicomotoras, permitindo-lhes, assim, autonomia na sociedade. (P6)

Bossa (2000) valida estas falas com a seguinte citação:

[...] o psicopedagogo pode colaborar na elaboração do projeto pedagógico, ou seja, através de seus conhecimentos ajudarem a escola a responder questões fundamentais como: O que ensinar? Como ensinar? Para que ensinar? Pode realizar o diagnóstico institucional para detectar problemas pedagógicos que estejam prejudicando a qualidade do processo de ensino-aprendizagem; pode ajudar o professor a perceber quando a sua maneira de ensinar não é apropriada à forma do aluno aprender; pode orientar professores no acompanhamento do aluno com dificuldades de aprendizagem; pode ainda, realizar encaminhamentos para fonoaudiólogos, psicólogos, neurologistas, psiquiatrias infantis, entre outros. (BOSSA, 2000). 
Verifica-se que quando abordado sobre o papel da psicopedagogia na escola, todos salientam que é extremamente importante na instituição escolar, pois a visão que este profissional tem, estimula o desenvolvimento de relações interpessoais, o estabelecimento de vínculos, a utilização de métodos de ensino compatíveis com as mais recentes concepções. Procura envolver a equipe escolar, ajudandoa a ampliar o olhar em torno do aluno e das circunstâncias de produção do conhecimento, ajudando o aluno a superar os obstáculos que se interpõem ao pleno domínio das ferramentas necessárias à leitura do mundo.

Portanto, o profissional da psicopedagogia propõe e auxilia no desenvolvimento de projetos favoráveis às mudanças educacionais, visando à descoberta e o desenvolvimento das capacidades da criança, bem como, pode contribuir para que os alunos sejam capazes de olhar esse mundo em que vive, de saber interpretá-lo e de nele ter condições de interferir com segurança e competência.

Quando perguntado aos alunos sobre as atividades que eles mais realizamem sala de aula

8. As atividades que mais realizamos e gostamos de fazer são osjogos, as brincadeiras e os desenhos;

9. As atividades que gosto mais de fazer em classe são os problemas, os exercícios escritos e a leitura;

10. Gostomais de ditados, exercícios, leituras;

11. Fazer trabalhos em grupo;

12 Trabalhos em grupos e ditados e jogos;

Quanto às respostas dadas por eles, destacam-se as seguintes atividades:ditados, exercícios, leituras, jogos, trabalhos em grupo, cópias.

Percebe-se que os alunos estão em ascensão no quesito aprendizagem, pelo esforço que estão fazendo, se dedicando às atividades, e pelo bom acompanhamento que estão tendo por parte dos professores, que por sua vez estão sendo orientados pelos pedagogos e psicopedagogos.

\section{Atividades que os alunos menos gostam}

Quando perguntado aos alunos sobre as atividades que eles menos gostam, deram as seguintes respostas: 


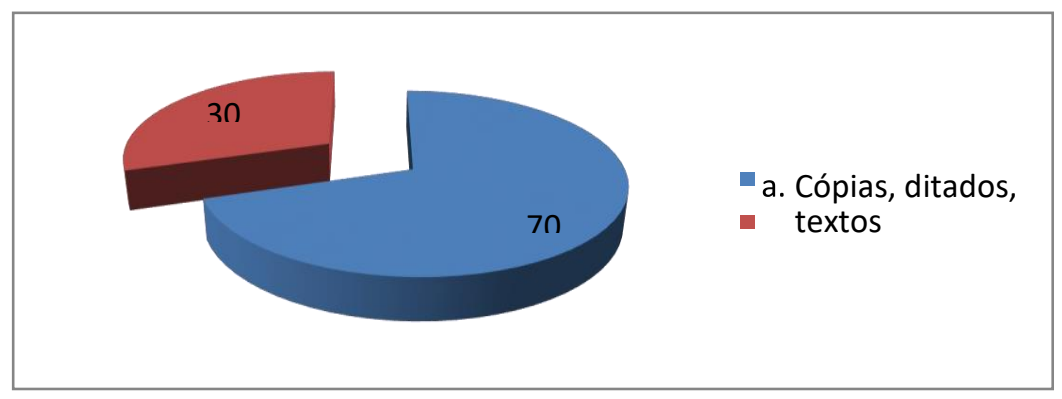

Gráfico 01: Atividades que os alunos menos gostam

Nas respostas dadas pelos alunos em relação às atividades que eles menos gostam de fazer em sala de aula. $70 \%$ dos alunos responderam: cópia, responder textos, ditado. Os outros 30\% restantes não responderam, ou não entenderam a pergunta.

\section{Fatores que facilitam a aprendizagem dos alunos}

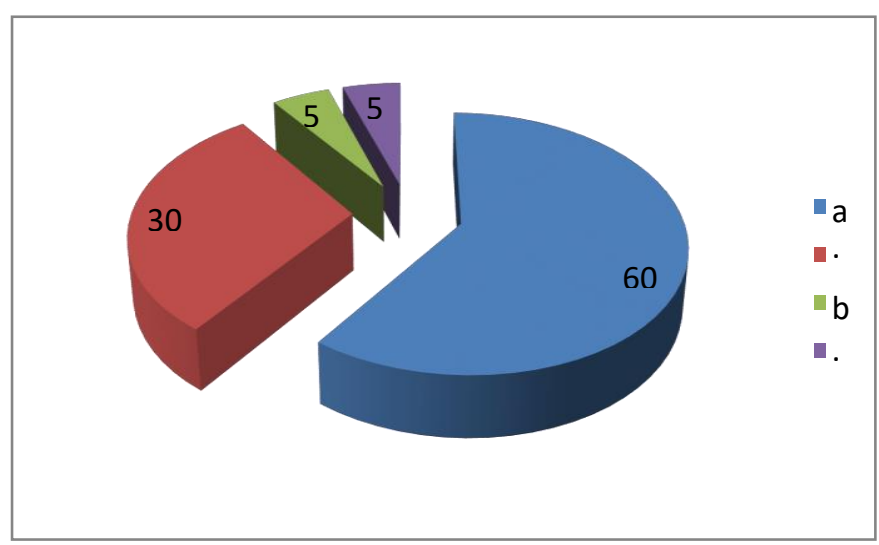

Gráfico 02: Fatores que facilitam a aprendizagem dos alunos.

a. Prestar atenção à aula;

b. Trabalho em grupo, com jogos e brincadeiras;

c. Desenhar;

d. Escrever, estudar e da professora.

Em relação aos fatores que facilitam a aprendizagem dos alunos em sala de aula, $60 \%$ disseram prestar a atenção à aula; $30 \%$ disseram que o trabalho em grupo através de jogos e brincadeiras; $5 \%$ optaram em desenhar e os 5\% restantes, ficaram com escrever, estudar e a professora. 


\section{As dificuldades sentidas em sala de aula pelos alunos}

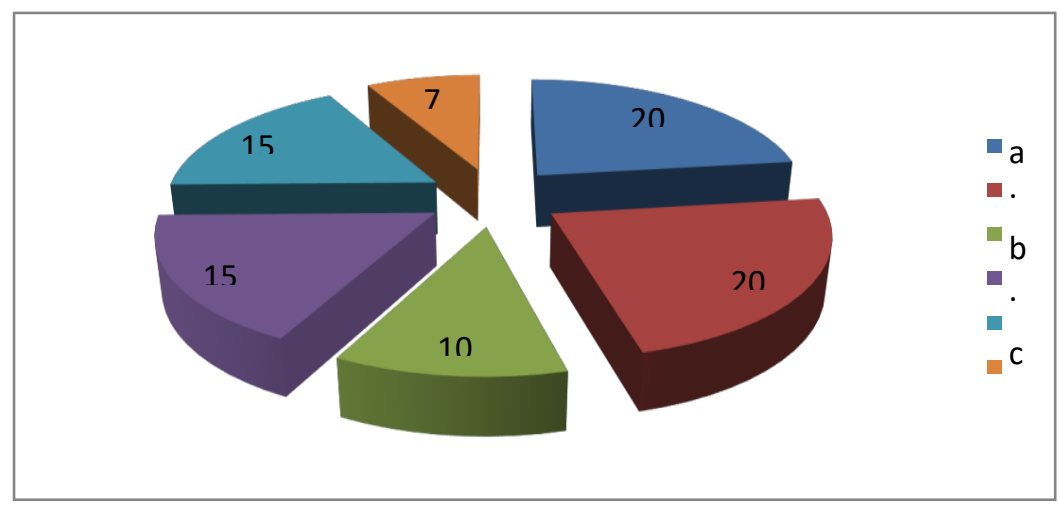

Gráfico 03: Dificuldades dos alunos

\section{a. Redação;}

b. Interpretação de texto;

$c$. Ler e escrever;

d. Aos probleminhas matemáticos;

e. Ao barulho;

f. Os deveres;

g. As continhas (matemática);

h. Nada destacou.

As dificuldades sentidas pelos alunos em sala de aula,20\% mencionaram fazer redação; $20 \%$ disseram interpretação de texto; $10 \%$ destacaram ler e escrever; $10 \%$ referiram-se aos probleminhas da matemática; $15 \%$ fez menção sobre o barulho; $7 \%$ fizeram referência aos deveres; $7 \%$ às continhas de matemática e os $4 \%$ restantes nada disseram. Estes resultados poderão ajudar para reflexão dos professores, quando da escolha das atividades para trabalhar com os alunos, serão com certeza excluídas aquelas que os alunos menos gostam.

\section{Conclusões}

O estudo psicopedagógico atinge seus objetivos quando, ampliando a compreensão sobre as características e necessidades de aprendizagem de determinado aluno, abre espaço para que a escola viabilize recursos para atender às necessidades de aprendizagem. Para isso, deve analisar o projeto político pedagógico, sobretudo quais as suas propostas de ensino e o que é valorizado como aprendizagem. Desta forma, o fazer psicopedagógico se transforma podendo se tornar uma ferramenta poderosa no auxílio de aprendizagem. 
Esse trabalho é um novo espaço, onde se aprofundam as questões sobre as dificuldades de aprender e com isso, vai construindo área a instalação da intervenção preventiva: os profissionais da psicopedagogia passam a sentir-pensar-agir as novas ações frente à aprendizagem dos conceitos, na escola. Nesse contexto, o profissional da psicopedagogia facilita a ampliação e a abertura para novas construções onde estejam presentes na integração cognitivo-afetivo-social e a transdisciplinaridade. $\mathrm{O}$ educador passa, nesse processo dialético, a rever o seu próprio processo de aprender. O profissional de psicopedagogia contribui intelectual, mas principalmente com vivencias e práticas por meio de oficinas.

Percebe-se que o psicopedagogo oferece um suporte instrumental aos professores como também oferece sugestões de atividades para a sala de aula; outras vezes sua atuação será individual ou em grupo com os alunos. É função deste profissional também oferecer um suporte emocional para professores que estão inseguros quanto a sua capacidade na aplicação de um método novo ou que estão com alunos com problemas de aprendizagem. Na medida em que o psicopedagogo ouve as dificuldades dos professores, esclarece sobre suas dúvidas, este se sentirá mais tranquilo, e ganhará mais confiança e proporcionará melhores condições para a aprendizagem.

Buscou-se nessa investigação, analisar a influência que tem a psicopedagogia na aprendizagem e nos relacionamentos interpessoaisdos alunos da escolamunicipal João Felix de Abreu.

Sobre conhecer a forma de atuação dos psicopedagogos da escola acerca de suas práticas, constatou-se que há uma necessidade de compreender as dificuldades de aprendizagem do aluno. A partir deste diagnóstico sente-se a necessidade de um reensino, que sejam trabalhadas atividades diferenciadas e criativas, que atendam as especificidades de cada aluno, de forma que envolvam, não só os ensinamentos conceituais, mais a base do convívio social e familiar, desenvolvendo os aspectos afetivo-cognitivos, sociais e motores.

Em termos de saber como acontece à intervenção da psicopedagogia na escola, constatou-se que a intervenção no ambiente escolar na perspectiva de resolução das dificuldades de aprendizagem dos alunos, além dos projetos interventivos já utilizados pelos professores, necessário se faz a intervenção curativa, objetivando diagnosticar intervindo individualmente nas necessidades destes.

Sobre analisar como os alunos estão aceitando a prática da psicopedagogia na escola, constatou-se diante das respostas dadas pelos alunos, que eles estão em ascensão no quesito aprendizagem, pelo esforço que estão fazendo, se dedicando às atividades, e pelo bom acompanhamento que estão tendo por parte dos professores. Já em relação às respostas dos professores, na aceitação dos alunos, percebe-se que os resultados são positivos quanto à aprendizagem, pois, a ação interventiva do psicopedagogo ressalta a aprendizagem múltipla construída no contexto do sujeito, no aproveitamento de antigas aquisições e na sua reestruturação psicológica, 
por intermédio da crença na sua capacidade de aprender sempre, pois houve amelhoria na aprendizagem em todos os níveis afetivo-cognitivo, social e emotivo.

Dessa forma, confirma-se a influência que tem a psicopedagogia na aprendizagemdos alunos. Constatou-se que a psicopedagogia compreende as dificuldades de aprendizagem que afetam o desenvolvimento intelectual, motor e emocional, que impedem o sujeito de aprender os conceitos e realidades internas e externas do seu entorno.

\section{Recomendações}

Recomenda-se a escola adote as práticas interventivas da psicopedagogia através de intervenções preventivas e curativas, para melhor desenvolver a aprendizagem dos alunos, não apenas em termos conceituais, mas em todos os aspectos afetivo-cognitivos sociais e motores.

Sugere-se ainda aos professores que se articulem na busca de diferentesformas de ensinamentos, sendo mais criativos, mais inovadores, utilização de ferramentas diversas, como também, fazendo uso dos conhecimentos que já possuem, evitandoassim, que se repita com os alunos os mesmos problemas de dificuldades de aprendizagem, que os levou a reprovação e aos conflitos emocionais pelos quais passaram.

Recomenda-se ainda que a escola incentive outros profissionais a desenvolverem pesquisas em todos os seus aspectos, procurando dessa forma fazerem uma auto-avaliação da aprendizagem dos alunos e dos professores que tem como papel fundamental a formação de um cidadão crítico, detentor do conhecimento conceitual, vivendo em harmonia com o meio educacional, familiar e social.

\section{Referências}

BOSSA, Nádia A. A psicopedagogia no Brasil: contribuições a partir da prática. Porto Alegre,Artes Médicas, 2000.

CASARIN, Nelson Elinton Fonseca; RAMOS, Maria Beatriz Jacques. Família e aprendizagem escolar. Rev. psicopedag., São Paulo, v. 24, n. 74, p. 182-201, 2007 .

CASTRO, Luciana Maria Cerqueira. A universidade, a extensão universitária e a produção de conhecimentos emancipadores. In: REUNIÃO ANUAL DA ANPED, 27., Caxambu, 2004. Anais... Caxambu: ANPEd, 2004. Disponível em: . Acesso em: 10 dez. 2012.

FREIRE, Paulo. Pedagogia da autonomia: saberes necessários à prática educativa. São Paulo: Paz e Terra (Coleção Leitura), 1996. 
LIBÂNEO, José Carlos. Didática. São Paulo:Corez,2004.

LÜCK, H. et al. A escola participativa: o trabalho do gestor escolar. 3. ed. Petrópolis: Vozes, 2005. 159 p., il. ISBN 85-326-3121-5.

RAUEN, F. J. Roteiros de investigação científica. Tubarão: Unisul, 1999/2002.

SCOZ, Beatriz. Psicopedagogia e realidade escolar. 13ª Ed. Rio de Janeiro: Vozes, 1994.

SEVERINO, Antonio Joaquim. Metodologia do Trabalho Científico. São Paulo: Cortez, 2007.

SEBER, M. G. Psicologia do pré-escolar: uma visão construtivista. São Paulo: Moderna, 1995.

SOLE, I. Orientação educacional e intervenção psicopedagógica. Porto Alegre: ARTMED, 2000.

TANAMACHI, E. R., \& Meira, M. E. M. (2003).A atuação do psicólogo como expressão do pensamento crítico em Psicologia e Educação. São Paulo: Casa do Psicólogo

WEISS, Maria Lucia. Psicopedagogia Clínica: uma visão diagnóstica dos problemas de Aprendizagem Escolar, Rio de Janeiro-,RJ: DP\&A, 2008.

\section{Como citar este artigo (Formato ABNT):}

ARRAES, Cybele B. de L.; LEITE, Maria Jucilene L. A Influência da Psicopedagogia na Aprendizagem dos Alunos da Escola Municipal João Felix de Abreu - Um Estudo de Caso. Id on Line Rev.Mult. Psic., 2018, vol.12, n.40, p.548-565. ISSN: 1981-1179.

Recebido: $26 / 04 / 2018$

Aceito: $10 / 05 / 2018$ 